\title{
Percepciones de los estudiantes de psicología sobre las relaciones interpersonales en el ámbito universitario: un estudio exploratorio*
}

\author{
Percepções de alunos de psicologia sobre as relações \\ interpessoais no ambiente universitário: um estudo \\ exploratório
}

\section{Perceptions of psychology students of interpersonal relationships in the college environment: an exploratory study}

\author{
Adriana Benevides Soares \\ Ana Maria Ribeiro de Seabra** \\ Ana Maria da Silva Porto \\ Cláudio de Almeida Lima \\ Tamiris de Abreu Fonseca \\ Zeimara de Almeida Santos \\ Universidade Salgado de Oliveira - \\ UNIVERSO, Brasil \\ Recibido: 20 de diciembre de 2013 \\ Revisado: 13 de febrero de 2014 \\ Aceptado: 21 de abril de 2014
}

\section{Resumen}

Esta propuesta tiene como objetivo identificar las percepciones de graduados a respecto de las relaciones sociales establecidas con la comunidad académica. Fue utilizada la técnica de Grupo Focal y Análisis de Contenido para cosecha y análisis de datos. Fueron listados dos niveles de dificultad relativos a las situaciones vivenciadas por los alumnos. Resalté la integración de los alumnos, la relación solícita entre los alumnos y profesores, funcionarios y gestores como fáciles; las subcategorías de la intolerancia y de la falta de tiempo para el relacionamiento entre los alumnos, la falta de compromiso docente, la arrogancia y descaso de los funcionarios y la valorización de la pos en detrimento de la graduación como difíciles. Se sugiere el desarrollo de programas en habilidades sociales con participantes del medio académico destacándose la escasez de trabajos con segmentos técnicos administrativos.

Palabras claves: grupo focal, habilidades sociales, relacionamientos interpersonales, universitarios, vivenciales académicas. 


\section{Resumo}

Objetivou-se identificar as percepções de graduandos a respeito das relações sociais estabelecidas com a comunidade acadêmica. Utilizou-se a técnica de Grupo Focal e Análise de Conteúdo para coleta e análise dos dados. Foram elencados dois níveis de dificuldade relativos às situações vivenciadas pelos alunos. Destacam-se a integração de alunos, a relação solícita entre alunos e professores, funcionários e gestores como fáceis; as subcategorias da intolerância e da falta de tempo para o relacionamento entre os alunos, a falta de compromisso docente, a arrogância e descaso dos funcionários e a valorização da pós em detrimento da graduação como difíceis. Sugere-se o desenvolvimento de programas em habilidades sociais com participantes do meio acadêmico destacando-se a escassez de trabalhos com segmentos técnicos administrativos.

Palavras-chave: Grupo focal, habilidades sociais, relacionamentos interpessoais, universitários, vivências acadêmicas.

\section{Abstract}

This article aims to identify the perceptions of undergraduates about the social relationships established in the academic community. Focus Group and Content Analysis were used for data collection and analysis. Two difficulty levels related to the situations experienced by students were listed. It is noteworthy that the subcategories of integration among the students, the good relationship between students and professors, staff and managers were considered easy situations; and subcategories of intolerance and lack of time for the relationship between the students, the lack of commitment of professors, the arrogance and indifference of the staff, and the appreciation of post-graduation over graduation were classified as difficult situations. We suggest the development of training programs in social skills with participants from the academic community, a rich environment of social interactions, highlighting in particular the shortage of work in this regard with the segment of administrative staff.

Keywords: Focus group, social skills, interpersonal relationships, university students, academic experiences.

\section{Introdução}

O Ensino Universitário vem apresentando expansão significativa, demandando reflexões sobre o desafio de manter uma educação de qualidade, de modo a favorecer o desenvolvimento pessoal, social e profissional dos graduandos, conduzindoos a resultados satisfatórios, tal qual acreditam Alberto e Balzan (2008). O crescimento da população universitária tem sido observado como realidade presente no processo de desenvolvimento da sociedade brasileira, passando de um número es- timado em aproximadamente 107.509 estudantes matriculados em 1962 para 2.125.958, em 1998. Em 2011, foram oferecidas 3.120 .192 vagas em mais de 2.300.000 cursos de Instituições Públicas e Privadas (Brasil, 2012). Essa população cada vez mais crescente tem apontado, segundo pesquisas realizadas em território nacional, deficiências no processo de adaptação ao ensino superior, ocasionada por diversos fatores (Soares, Mello, \& Baldez, 2011). As universidades brasileiras têm sido responsáveis pela capacitação e formação acadêmica de muitos jovens na última década. 
Segundo Alberto e Balzan (2008), a qualidade no Ensino Superior depende de fatores como: a valorização e capacitação dos docentes e funcionários técnicos administrativos, de programas políticopedagógicos que tenham por objetivos, além da formação técnico-acadêmica dos universitários, o compromisso com a formação ética e com a dignidade humana. A interação dinâmica positiva entre o estudante e o contexto acadêmico acontece quando o jovem adulto consegue gerir com êxito uma multiplicidade de tarefas acadêmicas, sociais, emocionais e vocacionais com que se depara ao ingressar no Ensino Superior. Esta interatividade, adicionalmente, fomenta o desenvolvimento pessoal e psicossocial dos jovens (Kumar, Silva, \& Paixão, 2007).

Nesse sentido, para uma educação universitária de excelência, tornam-se indispensáveis o compromisso com a socialização do saber, com o respeito à pluralidade de visões e práticas, com a formação cidadã, expressa através de relações sociais produtivas, mantidas entre os diferentes segmentos da comunidade universitária (Washington et al., 2006). Alberto e Balzan (2008) corroboram essa visão, afirmando que o processo educacional não se restringe apenas às aulas, sendo viabilizado também pela articulação entre todos os membros da comunidade universitária: alunos, professores, técnico-administrativos e gestores. Por sua vez, Chauí (2003), Silva e Nascimento (2012) e Roncaglio (2004) mostram, em seus estudos sobre as novas perspectivas da universidade pública, que propostas de interações democráticas e de respeito à diversidade se estendem também à socialização das diferentes abordagens teóricas existentes, cujo acesso deve ser proporcionado ao corpo discente das universidades de modo a contribuir para uma visão abrangente e não tendenciosa.

Além de estarem dentre as metas da instituição universitária a preparação dos jovens para o trabalho e para a participação social crítica e ética, como preconizam Washington et al. (2006), a qualidade dos relacionamentos interpessoais é uma preocupação existente para esse segmento (Soares, A. B. e Del Prette, Z., 2013), cabendo à universidade considerar a possibilidade de desen- volver programas de treinamento de habilidades sociais, que possam contribuir para o bem-estar psicossocial dos estudantes no relacionamento com seus pares (Soares, Guisande, Almeida, \& Páramo, 2008). As habilidades sociais têm efetivamente se apresentado como uma característica comportamental presente nos estudantes universitários como realidade facilitadora nas relações interpessoais e no processo de adaptação acadêmica (Del Prette \& Del Prette, 2010; Del Prette, Del Prette, \& Barreto, 2006). Para Costa e Oliveira (2010), a maturidade psicossocial e a preparação acadêmica dos estudantes influem de maneira significativa no processo de adaptação, pois capacidades pessoais como resiliência, objetivos claros, alcance de autonomia e domínio sobre o conhecimento são facilitadores neste processo. O mesmo propõe Seco, Casimiro, Pereira, Dias e Custódio (2005) ao considerar as exigências e desafios do contexto universitário apontando para a necessidade de certos recursos que precisam ser contemplados pelo universitário, competências individuais, emocionais e sociais, considerando a importância das relações familiares, envolvimento em atividades extracurriculares que possibilitam oportunidades de desenvolver aptidões interpessoais. Também para Parker, Summerfeldt, Hogan e Majeski (2004), um repertório de habilidades sociais precisa ser desenvolvido por parte dos estudantes que entram no Ensino Superior a fim de facilitar a adaptação dos mesmos, pois quando este repertório não existe, pode acarretar um desempenho menos satisfatórios no aproveitamento do curso, reprovações, prolongamento do período de conclusão e psicologicamente o desenvolvimento de baixa autoestima e baixo autoconceito. Os autores consideram a associação entre o sucesso acadêmico e as competências emocionais e sociais como necessária quando se consideram aspectos envolvidos nas relações interpessoais.

Algumas questões que se colocam com o crescimento do Ensino Superior e que podem ter relação com a qualidade dos cursos, comprometendo-a, são aspectos institucionais tais como: o pouco envolvimento docente nas atividades acadêmicas, a inadequação do atendimento dos funcionários aos estudantes e a insegurança nos campi (Andriola \& Andriola, 2009). Chauí (2003) aponta a contra- 
tação de professores para o trabalho temporário como aspecto prejudicial ao estabelecimento de vínculos entre os docentes e as atividades que desenvolvem na Universidade, uma vez que seu trabalho é interrompido pelo término da contratação, sem que sejam levados em conta os prejuízos que tal ação administrativa acarreta para os aspectos psicopedagógicos presentes no processo ensino aprendizagem. Chauí (2003) acrescenta a importância de reavaliar os currículos universitários, de modo que o Ensino Superior não se restrinja à transmissão de conhecimentos, sendo excluído o caráter formativo que a educação possui.

No que diz respeito ao segmento dos funcionários técnico-administrativos, apesar da vivência institucional que possuem e da interdependência existente entre as atividades administrativas e pedagógicas, pesquisas mostram que eles não se percebem como elementos participantes da vida universitária (Alberto \& Balzan, 2008). Em sua pesquisa, Silva (2010) ratifica tal visão e destaca a importância da inserção e consequente compromisso desse segmento na vida universitária. Quanto às interações sociais referentes ao segmento dos gestores, Silva e Nascimento (2012), assim como Roncaglio (2004), consideram de extrema importância o estabelecimento de relações solícitas entre alunos e gestores, descrevendo o quanto é motivador tê-los como ponto de apoio na jornada acadêmica. Acreditam que para ter uma gestão de qualidade, como ressaltam, é necessário que seja democrática e haja um comprometimento de todo grupo universitário com as atividades do contexto acadêmico.

Já em relação à insegurança nos campi, Branco, Cubas, Alves, Carvalho e Natal (2013) afirmam que a investigação de programas sobre segurança nas instituições universitárias faz-se urgente e necessária. Buscaram informações na literatura e em endereços eletrônicos a respeito da criação de programas sobre segurança de instituições de ensino superior estrangeiras. Segundo os autores, existem apenas informações na mídia, mas faltam na literatura artigos ou estudos que embasem o problema no Brasil e que propiciem contribuições e iniciativas decisivas por parte das autoridades envolvidas no contexto. Embora o estudo tenha sido entre quatro universidades estrangeiras, permitiu identificar semelhanças e/ou diferenças para o tema em questão, bem como, encontrar soluções que possam colaborar na criação de modelos de segurança eficientes para as instituições brasileiras.

Nessa direção, além dos fatores conjunturais que interferem na boa qualidade do Ensino Superior, o desenvolvimento de competências sociais vem sendo estudado como sendo fundamental aos relacionamentos interpessoais (Del Prette \& Del Prette, 2010), estabelecidos entre todos os segmentos da comunidade acadêmica. De acordo com os autores, as dificuldades interpessoais afetam a exposição dos conhecimentos acadêmicos, o bem-estar físico e psicológico dos indivíduos, no caso desse estudo, alunos, professores, funcionários e gestores, que têm a interação como base. É possível que a má qualidade de ensino se deva também à ausência de relações sociais produtivas e necessárias às situações interpessoais de todos os participantes da comunidade acadêmica, demonstrando a relevância do desenvolvimento de competências sociais ser focado como demanda dentro do ambiente universitário.

Dessa forma, considerando a importância que as habilidades sociais têm na promoção do bom desempenho social de todos que participam da vida universitária e da contribuição que oferece à qualidade da educação com a qual estão envolvidos, esta pesquisa apresenta como objetivo conhecer as percepções de graduandos de Psicologia de uma universidade pública a respeito das relações sociais estabelecidas com os diferentes segmentos da comunidade acadêmica: alunos, professores, funcionários e gestores.

\section{Método}

\section{Participantes}

Participaram deste estudo qualitativo e exploratório doze estudantes universitários de uma instituição pública de Ensino Superior do curso de Psicologia do Estado do Rio de Janeiro. As informações demográficas dos participantes são apresentadas na Tabela 1. 
Tabela 1

Informações demográficas

\begin{tabular}{cccccc}
\hline Participantes & Idade & Gênero & Estado Civil & Período & Classificação Sócio Econômica \\
\hline P1 & 21 & F & S & $3^{\circ}$ & B2 \\
P2 & 19 & M & S & $3^{\circ}$ & B2 \\
P3 & 19 & F & S & $3^{\circ}$ & B1 \\
P4 & 21 & F & S & $3^{\circ}$ & C1 \\
P5 & 21 & F & S & $3^{\circ}$ & B1 \\
P6 & 21 & F & S & $3^{\circ}$ & C1 \\
P7 & 22 & F & C & $8^{\circ}$ & B1 \\
P8 & 22 & F & S & $3^{\circ}$ & B2 \\
P9 & 20 & F & S & $3^{\circ}$ & C1 \\
P10 & 21 & F & S & $3^{\circ}$ & B2 \\
P11 & 20 & F & S & $3^{\circ}$ & B2 \\
P12 & 20 & F & S & $3^{\circ}$ & C1 \\
\hline
\end{tabular}

Dos participantes, 11 eram do sexo feminino, com a idade média de 18, $9(D P=1,93)$, em quase sua totalidade, solteiros $(90,1 \%)$. Todos eram estudantes de Psicologia, sendo apenas um aluno do $8^{\circ}$ período e os demais do $3^{\circ}$ período. No que se refere ao nível socioeconômico, houve predomínio de três classes encontrando-se 33,33\% dos estudantes na classe B1, 41,67\% na classe B2 e 33,33\% na classe C1(ABEP, 2011).

\section{Procedimentos de coleta de dados}

Os estudantes, instruídos pelos pesquisadores, responderam ao Questionário Critério Brasil (ABEP, 2011) que avalia o nível socioeconômico e o grau de instrução do chefe da família permitindo a categorização em classes sociais (A1, $A 2$, B1, B2, C1, C2, D e E). Em seguida, foi utilizada a técnica do grupo focal (Barbour, 2009) que permite a compreensão de discursos construídos coletivamente e a identificação de sentimentos, percepções, atitudes, ideias dos participantes a respeito de um determinado assunto. 0 estudo em questão objetivou conhecer as concepções dos estudantes universitários acerca das situações sociais e acadêmicas vivenciadas nas relações interpessoais com os demais alunos, professores, gestores e funcionários técnicos administrativos. Os participantes foram selecionados no ambiente universitário, por conveniência, pelos autores da pesquisa, sendo convidados verbalmente a participarem do grupo focal proposto.

\section{Procedimentos éticos}

O projeto de pesquisa foi aprovado pelo Comitê de Ética em Pesquisa. No momento da introdução do projeto do grupo focal, os estudantes foram esclarecidos sobre os objetivos do estudo, participação voluntária, possibilidade de desistência em qualquer momento, garantia de sigilo dos dados e assinaram o Termo de Consentimento Livre e Esclarecido (TCLE).

\section{Procedimentos de análise de dados}

As falas que ocorreram durante o grupo focal sobre as vivências acadêmicas foram gravadas e transcritas integralmente, sendo feitos ajustes quanto à grafia de alguns termos utilizados. A partir da leitura das conversas transcritas, foi realizada a Análise de Conteúdo que segundo Bardin (2009), consiste na investigação sistemática dos conteúdos manifestados nas comunicações orais a fim de extrair os núcleos de sentido possíveis. Iniciou-se com a pré-análise e exploração do material, passando-se, em seguida, para o tratamento dos resultados, a inferência e a interpretação. 


\section{Apresentação e discussão dos resultados}

As respostas dadas durante o grupo focal acerca da percepção dos alunos a respeito das relações com os diferentes segmentos da comunidade universitária foram exploradas e analisadas, tendo sido identificados, previamente, núcleos temá- ticos que possibilitaram a organização de duas categorias referentes às situações consideradas como difíceis ou fáceis pelos estudantes junto aos colegas, professores, técnicos administrativos e gestores. Dando continuidade a análise das falas, foram identificadas subcategorias dentro das categorias já organizadas, resultando na seguinte distribuição apresentada na Tabela 2.

Tabela 2

Categorias de situações vivenciadas como fáceis e difíceis

\begin{tabular}{|c|c|c|}
\hline \multirow{11}{*}{$\begin{array}{l}\text { Categoria 1: } \\
\text { Situações vivencia- } \\
\text { das como fáceis }\end{array}$} & & respeito às diferenças \\
\hline & & integração do grupo de alunos \\
\hline & atuno-atuno & aproximação por afinidade \\
\hline & & companheirismo \\
\hline & & relação solícita com alunos \\
\hline & aluno- funcionários & $\begin{array}{l}\text { relação de compreensão do aluno com o trabalho do funcionário, } \\
\text { disponibilidade em ajudar o aluno }\end{array}$ \\
\hline & & professor solícito \\
\hline & & método de ensino adequado \\
\hline & aluno-protessor & flexibilidade do professor \\
\hline & & comprometimento do professor \\
\hline & aluno-gestores & relação solícita entre alunos e professores \\
\hline \multirow{14}{*}{$\begin{array}{l}\text { Categoria 2: } \\
\text { Situações vivencia- } \\
\text { das como difíceis }\end{array}$} & & intolerância com os colegas \\
\hline & aluno-aluno & falta de tempo para as relações interpessoais \\
\hline & & dificuldade para realizar trabalho em grupo \\
\hline & & arrogância e descaso \\
\hline & aluno-funcionários & individualismo \\
\hline & & não cumprimento da função \\
\hline & & dificuldade com didática do professor \\
\hline & alunn-nrofecser & falta de autoridade \\
\hline & aturno-protessol & falta de compromisso do professor \\
\hline & & linguagem docente inadequada \\
\hline & & valorização da pós-graduação em detrimento da graduação \\
\hline & aluno-instituvicão & insegurança no campus \\
\hline & 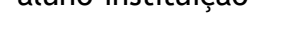 & falta de espaço para novas abordagens \\
\hline & & alternância de professores na mesma disciplina \\
\hline
\end{tabular}


Uma vez organizadas as categorias e respectivas subcategorias, foram realizadas interpretações e inferências sobre o material. Na relação alunoaluno foram encontradas sete categorias, cujas mais significativas falas foram transcritas a seguir. As primeiras três se referem a situações julgadas como difíceis e as outras quatro, como fáceis: Intolerância com os colegas: “... você não pode falar isso porque meu pastor, porque meu não sei...", "Há preconceito também quanto à sexualidade."; Falta de tempo para relações interpessoais: "Todo mundo tem uma vida corrida, tem gente que faz estágio, trabalha, estuda fora, faz curso, vem correndo e os intervalos são de dez minutos, então não têm tempo para parar e se conhecer melhor."; Dificuldade para realizar trabalho em grupo: "Ninguém consegue chegar até o final porque sempre tem confusão." As falas evidenciam momentos de vivências consideradas difíceis entre os estudantes em que relações interpessoais estabelecidas de forma inadequada podem afetar os resultados acadêmicos, ratificando os dados obtidos por Soares A. B. e Del Prette, Z. (2013).

Apesar dos conflitos observados pelo grupo, foram destacadas também situações interpessoais percebidas como fáceis: Respeito às diferenças: "Por mais que a gente discuta, a gente não tem preconceito, a gente sabe respeitar o espaço do outro, meu direito termina quando começa o do outro. É assim o esquema lá na sala.”; Integração do grupo de alunos: "Eu convivo super bem com o pessoal, quem passa por mim eu brinco (...), na sala em si a gente não tem problema. Até com os alunos de fora, porque com o calendário novo, há alunos de outros períodos que estudam conosco. A gente se dá super bem, não tenho problemas com isso não."; Aproximação por afinidade: "Então a gente acaba fazendo amizade com pessoas mais próximas, mais parecidas." "Pra fazer amizade, no meu caso, não foi nem questão de proximidade, mas de afinidade (...) é afinidade política, social, econômica, é tudo questão de afinidade."; Companheirismo: "Eu não tenho muito contato com todos os veteranos, mas com o meu veterano sim, porque me ajuda muito com essas coisas de trabalho e prova. Ele ajuda muito a gente.". Nas três transcrições se percebe que o relacionamento interpessoal entre os estudantes de modo a estabelecer e manter relações afetivas é uma preocupação dos universitários, sugerindo, tal qual Soares A. B. e Del Prette, Z. (2013), que a convivência no meio acadêmico contribui para o desenvolvimento interpessoal. Acrescenta-se que a categoria companheirismo também foi encontrada no grupo focal realizado por Soares A. B. e Del Prette, Z. (2013), corroborando a existência da ideia de que relações cooperativas e de respeito mútuo são consideradas relevantes pelos alunos.

Quanto às situações interpessoais acadêmicas nas relações aluno-instituição quatro categorias julgadas como difíceis foram encontradas para agrupar os diálogos dos alunos: Valorização da pós em detrimento da graduação: "a universidade dá muito mais bola para a pós-graduação do que para a graduação, a gente sai prejudicada porque muitos professores escolhem a graduação só para cumprirem horário...". Nesta fala é possível observar o incômodo relatado pela aluna, em função da valorização da pós em detrimento da graduação. $\mathrm{Na}$ percepção dos estudantes universitários a pesquisa e a pós-graduação exigem um engajamento dos professores que visa à quantidade de publicações, colóquios e congressos, bem como a produção crescente de relatórios, tal qual discorre Chauí (2003). Desse modo, segundo a mesma autora, a docência na graduação é apresentada como uma transmissão rápida de conhecimentos, em que os professores utilizam, preferencialmente, materiais ricos em ilustrações, de fácil leitura e compreensão, para otimizar o tempo com os alunos dentro da sala de aula. Insegurança no campus: “... já quase fui assaltada aqui dentro da universidade até foi nesse corredor aqui do nosso andar mesmo.". O problema de segurança dentro dos campi universitários, principalmente dentro das grandes universidades é recorrente e acontece a nível nacional, como afirma Branco et al. (2013, p. 184) em um estudo que sugere a necessidade de criar um "modelo de segurança eficiente". Falta de espaço para novas abordagens: "Psicologia é uma área bem ampla e às vezes tem várias abordagens que a gente não tem acesso na graduação nem como eletiva". Repensar uma reestruturação do currículo para atualizar a grade de acordo com as necessidades informacionais e disponibilizar a 
opção de transitar em outras áreas interdisciplinares com matérias optativas, proporcionaria novos conhecimentos aos discentes e seria de grande valia para formação profissional e melhor atuação no mercado de trabalho (Chauí, 2003). Alternância de professores na mesma disciplina: “...essa troca toda hora de professor diferente do outro, isso me atrapalha muito.”. Há uma rotatividade muito grande de professores temporários em universidades públicas, levando os alunos a sentirem dificuldades na compreensão dos conteúdos ministrados em determinadas disciplinas, em decorrência dessa contratação de docentes por tempo determinado. Para Chauí (2003), o recrutamento destes profissionais é feito sem levar em consideração se dominam ou não o campo de conhecimento de sua disciplina, o que dificulta a vida acadêmica dos estudantes.

Quanto às situações interpessoais acadêmicas consideradas fáceis nas relações aluno-gestores foi encontrada apenas uma categoria para a fala que a caracteriza: Relação solícita entre alunos e gestores: "O reitor se mostrou muito solícito com a empresa júnior de Psicologia, eu fiquei muito satisfeita mesmo, me motivou bastante." Segundo Roncaglio (2004) é muito importante a existência de uma relação democrática não só entre o aluno e o professor, mas sim, de toda a comunidade acadêmica, fazendo-se necessário um comprometimento dos gestores com a instituição e os diversos setores da universidade, para que haja uma gestão de qualidade. Tal fato é confirmado por Silva e Nascimento (2012), que também afirmam que os discentes se preocupam com todas as relações interpessoais estabelecidas no contexto acadêmico, com os pares, professores gestores e servidores administrativos.

Nas relações entre alunos e funcionários estão presentes três situações acadêmicas percebidas como difíceis: Arrogância e descaso: “... o tempo todo que a gente vai lá eles ficam no computador, ignoram a gente, quando falam com a gente, falam de longe.", "Ela foi super ignorante comigo, eu fui procurar um professor, ela me deu um fora enorme e eu dei outro fora enorme nela.". Dessa forma, aparece nas falas dos estudantes, a dissonância entre os aspectos preconizados pe- los Projetos Políticos Pedagógico das universidades que dizem respeito às funções destinadas aos funcionários técnicos administrativos e à prática profissional por eles desenvolvida no cotidiano acadêmico. Dentre alguns princípios norteadores que constam no referido documento estão a relevância do desenvolvimento de seus recursos humanos, a capacitação continuada dos servidores, uma gestão estruturada democraticamente que contribua para a participação ativa da comunidade universitária, da qual os técnicos-administrativos fazem parte, além do desenvolvimento de relações sociais produtivas e de serviço (Alberto \& Balzan, 2008). Assim sendo, os dados colhidos neste estudo corroboram os resultados encontrados por Soares et al. (no prelo), no qual as interações sociais estabelecidas entre alunos e funcionários também são percebidas pelos universitários como desprovidas de acolhimento e resposta para as demandas administrativas dos alunos, além da falta de preparo para o exercício profissional, como ilustra as seguintes categorias: Não cumprimento da função, segundo a visão dos estudantes: "Não, eles não abrem a sala e sabem que nossas aulas começam 12 e meia. Se eles... sabem em que sala vai ter aula, em que sala não vai ter, não é mais que obrigação deles, porque desculpe, mas eles recebem pra isso."; Individualismo: "Só uma pessoa sabe das coisas, o resto não (...) uma pessoa muito ignorante é a que sabe.". Apesar da importância dada à participação dos servidores técnicos administrativos na discussão de temas de interesse de todos os segmentos da universidade, como forma de gestão e de organização democráticas, os valores que norteiam a atuação desse segmento, tais como: qualidade de trabalho, cidadania, ética e cooperação, preconizados por Silva (2010), na percepção de muitos estudantes não é o que parece prevalecer nesse segmento.

Nesse sentido, o aperfeiçoamento dos servidores técnico-administrativos pode comportar programas que envolvam o desenvolvimento de habilidades sociais, já que o contexto do trabalho nas universidades é rico em interações, requerendo competência social de todos os envolvidos (Del Prette, Del Prette, \& Barreto, 2006). Vale acrescentar que Silva (2010) assinala, ainda, a escassez de trabalhos envolvendo o segmento de técnico- 
administrativos, cujo aperfeiçoamento profissional e desenvolvimento de competências interpessoais muito contribuiriam para a adaptação do estudante à universidade (Silva \& Nascimento, 2012). Contudo, os universitários reconhecem existir vivências acadêmicas que destoam das anteriores por serem percebidas como fáceis, sendo apresentadas três a seguir: Relação solícita dos funcionários com os alunos: "Eles nunca foram ignorantes nem nada comigo (...)", "Tem um menino que eu achei ele novo na secretaria, no dia que eu fui ele me atendeu super bem, porque eu perguntei e ele falou: Não sei, mas peraí só um instantinho. Ele foi procurar a pessoa, perguntou e voltou com a informação.", "O pessoal do SPA atende a gente super bem, é ótimo.". Parece que, como preconizam Alberto e Balzan, (2008) um grupo de funcionários demonstra ter consciência da importância de seu trabalho para a vida da instituição. No entanto, tal categoria diverge dos achados de Andriola e Andriola (2009), cujo estudo encontrou nas falas discentes referências ao atendimento inadequado que funcionários da graduação de Educação da Faculdade Federal do Ceará concedem aos universitários. Disponibilidade dos funcionários em ajudar os alunos: " $A$ porta estava com problema. Eu passei na secretaria e pedi para consertar, aí (...) de manhã quando estava fazendo estágio e tinha alguém limpando a porta eu falei: por favor, moço, será que o senhor pode passar um oleozinho, eu trago e ele falou: Tá bom!". A transcrição se coaduna com o que Silva (2010) defende quando se refere à importância da participação do funcionário para assegurar a qualidade da atividade administrativa relacionada ao ensino na graduação. Também confirma a importância do servidor técnico-administrativo em promover a compatibilização entre os objetivos institucionais e as demandas da comunidade escolar, dentre os quais estão os estudantes. Relação de compreensão do aluno com o trabalho do funcionário: "A gente chega aqui, muitas vezes não sabe, eles têm que parar o que estão fazendo. A questão de não abrir a sala, claro pra gente seria o melhor chegar aqui e ter a sala aberta, mas (...) é uma questão de responsabilidade e com certeza se eles não passam a chave é porque alguém deu essa ordem. Então não pode simplesmente pegar e dar uma chave e se por acaso acontecer alguma coisa a responsabilidade vai ser de quem entregou". Os estudantes universitários apresentam, também, uma visão humanizada do servidor técnico administrativo, considerando o funcionário como uma pessoa que faz, pensa, realiza e vive (Alberto \& Balzan, 2008).

Conforme a abordagem de Barbour (2009) e considerando a dinâmica do grupo focal, foi possível entender que as falas dos participantes de modo geral fundamentam sua opinião, quando envolvidos na discussão categorizada na relação alunoprofessor. As subcategorias elencadas para as situações acadêmicas referentes à relação alunoprofessor foram quatro consideradas difíceis, a saber: Dificuldade com didática do professor: “... ele não tem uma didática do meu ponto de vista, eu vejo assim ... ele não segue a ementa, com certeza, ele não dá a matéria..." Para Ribas (2005) a utilização da ementa não deve ser vista apenas como um instrumento obrigatório, mas sim sob uma perspectiva pedagógica, como previsão de atividades unidas a um projeto de ensino objetivando o desenvolvimento em etapas sequenciais que mobilizem o aluno no processo ensino-aprendizagem. Ribas (2005) acrescenta que um professor é muito mais que conhecimento pedagógico geral, é conhecimento de alunos, ensino, currículo, contexto, objetivos e propósitos. Falta de autoridade do professor: "Ele chega na sala de aula, tá a maior bagunça na sala ,entra na sala com uma media 6, 7 alunos e aí vão saindo um monte ..." Sob esta perspectiva, Novais (2004) afirma que historicamente a relação aluno-professor foi marcada pela associação autoridade e autoritarismo. A perda da autoridade do professor, segundo Morais (2001), está associada à perda de poder em determinar as ações dos alunos e do direito de exercer autoridade. Ainda nesta mesma direção, Roncaglio (2004) afirma que o fato do professor, ao longo do tempo, ter perdido prestígio e respeito perante a sociedade, acabou afetando sua posição hoje na sala de aula. Em pesquisa realizada por eles a maior dificuldade nesta relação de autoridade está na indisciplina dos alunos, o qual gera que alguns professores usem de autoritarismo com a finalidade de fazer com que os estudantes colaborem com a disciplina em sala de aula, no lugar de bem desenvolverem 
a consciência da liberdade preconizada por Freire (2009). Falta de compromisso do professor: “... eu não vejo ele comprometido com a educação, porque ele não cobra presença, as pessoas não assistem a aula dele e todo mundo passa, com 100\% de presença.", “... a gente tem o professor e eles colocam os mestrandos para darem aula.....fica complicado...", "Professor que falta e não avisa.". Desta forma, a visão dos alunos se coaduna com o que Freire (2011) preconiza: o ato de ensinar é um compromisso social de superação e transformação de sujeitos - alunos e professores - em seres reflexivos, capazes de assumirem responsabilidades a serem reexaminadas constantemente. Linguagem docente: "Muitos professores por saberem demais e pegarem uma turma que está começando, não falam de modo que os alunos compreendam.". O relato dos estudantes demonstra a necessidade dos docentes universitários facilitarem o acesso aos saberes socialmente construídos, de forma que os alunos possam se apropriar dos conhecimentos e desenvolver visões críticas em um ambiente de aprendizagem em que sejam sujeitos ativos da aprendizagem (Freire, 2009).

Já os resultados obtidos nas situações fáceis revelaram que: Professor solícito:"Gente, ele é inteligentíssimo. Se você pegar ele no corredor para explicar uma dúvida, ele vai explicar uma matéria que não é nem a dele". A transcrição reflete que a importância da relação aluno professor para o sucesso acadêmico e interesse pela disciplina é fundamental, especialmente quando este professor se preocupa em criar uma atmosfera agradável e harmoniosa em favor da aprendizagem. Segundo Perrenoud (2000) os professores não possuem apenas saberes, mas também competências profissionais e pessoais, dentre as quais o bom relacionamento do professor com o aluno se encontra. Flexibilidade do professor: "Eu percebo que ele sempre nos ouve e ele tem praticado aquilo que nós temos falado também. É uma troca, eu acho que a relação dele com a turma mudou porque ele percebeu que a turma não gostava tanto do jeito que ele falava, do jeito que ele agia (...)”. A fala transcrita reflete o que Capitanio (2003) pensa ao afirmar que relacionar-se significa interagir um com o outro. Para este autor, o processo de ensino aprendizagem deve afastar-se gradativamente do processo de ensino tradicional, em que o professor é detentor de todo o saber e poder. Também Vasconcellos (2004) acredita que o relacionamento interpessoal no ambiente acadêmico é capaz de exercer significativa influência no processo de formação do aluno, possibilitando desenvolver as potencialidades dos mesmos para o exercício consciente da cidadania. Comprometimento do professor com os alunos: “(...) Ele está querendo nos levar pra um congresso fora do Rio. Então, ele está nos abrindo portas, ele está sendo assim, um professor maravilhoso pra gente." "... ele se resume como uma pessoa comprometida, ele é muito comprometido no que ele faz. Ele nunca faltou aula, não que eu me lembre, chegava nos horários certos pra dar aula." Tal perspectiva corrobora o que Perrenoud (2000) afirma: que o professor é responsável não apenas por transmitir conhecimento, mas por formar opiniões e valores, assumindo assim um papel significativo tanto para o desenvolvimento de competências atitudinais, dentre as quais os desempenhos sociais habilidosos estão, como conceituais.

\section{Considerações finais}

A expansão do Ensino Superior e a qualidade da educação por ele promovida mobilizam pesquisadores. Dando prosseguimento a esta preocupação, este estudo procurou analisar, dentre os muitos fatores que interferem no processo de ensino, a percepção de graduandos de Psicologia a respeito das relações interpessoais estabelecidas entre eles e professores/funcionários/gestores. As falas transcritas evidenciaram que as relações sociais estabelecidas entre os membros da comunidade acadêmica são percebidas como apresentando desempenho social insatisfatório no que diz respeito às relações entre alunos/alunos, alunos/ professores e alunos/funcionários. Vale ressaltar que o relacionamento entre alunos/gestores é vista como satisfatória, uma vez que as interações estabelecidas apresentam comportamentos de civilidade, empatia e assertividade, aspectos relevantes dentro do campo teórico das habilidades sociais.

Em relação às limitações desse trabalho, pode ser destacado o fato dos participantes da investigação 
pertencerem a apenas um curso, o de Psicologia, sendo sugeridos estudos com amostras de universitários de outras graduações, a título de comparação. Outra limitação do estudo diz respeito ao fato de na literatura sobre o tema, estudos sobre a percepção de universitários sobre as relações sociais estabelecidas com os demais segmentos da comunidade universitária serem escassos.

Dessa forma, sugerem-se investimentos em módulos de treinamento de habilidades sociais destinados aos funcionários técnicos administrativos, professores e alunos universitários, tanto no currículo das instituições, quanto nas atividades profissionais dos demais membros, professores e funcionários técnico-administrativos, a fim de promoverem desempenhos sociais competentes, prevenindo e minimizando aspectos que possam interferir na qualidade da educação a que a universidade se destina.

Vale acrescentar a relevância da continuidade dos estudos sobre a importância das habilidades sociais de todos os que participam da vida acadêmica, em especial de professores, funcionários e alunos, para o desenvolvimento de desempenhos éticos que contribuam para a qualidade da educação pretendida pelas instituições de Ensino Superior.

\section{Referências}

Alberto, J. M. \& Balzan, N. C. (2008). Avaliação de projeto político-pedagógico pelos funcionários: Espaços e representatividade. Avaliação: Revista da Avaliação da Educação Superior (Campinas), 13(3), 745-776.

Andriola, W. B., \& Andriola, C. G. (2009). Avaliação da qualidade educacional da Faculdade de Educação (FACED) da Universidade Federal do Ceará (UFC). [Online]. Ensaio: Avaliação e Políticas Públicas em Educação, 17(62), 153-168. Recuperado de http://www.scielo.br/pdf/ensaio/v17n62/a08v1762.pdf [2013, 21 de abril].

Associação Brasileira de Empresas de Pesquisa (ABEP). (2011). [Online]. Dados com base no Levantamento Socioeconômico de 2009. Re- cuperado de http://www.abep.org [2013, 9 de março].

Barbour, R. (2009). Grupos focais. Porto Alegre: Artmed.

Bardin, L. (2009). Análise de Conteúdo. Lisboa, Portugal: Edições 70.

Branco, F. C., Cubas, V. O., Alves, R., Carvalho, D., \& Natal, A. (2013). Segurança no campus: Um breve levantamento sobre as políticas de segurança na USP e em universidades estrangeiras. Revista Brasileira de Segurança Pública, 7(1), 182-198.

Brasil. (2012). Ministério da Educação/ Instituto Nacional de Estudos e Pesquisas Educacionais Anísio Teixeira (INEP). Relatório do I Encontro Nacional do Censo da Educação Superior.

Capitanio, A. M. (2003). Relacionamento não verbal na Educação Física. [Online]. Revista digital, 9(64). http://www.efdeportes.com/ efd64/noverb.htm [2013, 24 de abril].

Castagnoli, C. A. (2003). Atividades esportivas, culturais e cooperativas como meio de superação no relacionamento interpessoal na escola. [Online]. http://www.diaadiaeducacao.pr.gov.br/portals/pde/arquivos/389-4.pdf [2013, 3 de março].

Chauí, M. (2003). A universidade pública sob nova perspectiva. [Online]. Revista Brasileira de Educação, (24), 5-15. http://www.scielo.br/ pdf/rbedu/n24/n24a02.pdf [2013, 6 de junho].

Costa, L. \& Oliveira, M. (2010). Vivências e satisfação acadêmica em alunos do ensino superior. In S. Gonçalves, D. Soeiro \& S. Silva (Eds.). Cadernos de Pedagogia no Ensino Superior, 13, 13-32.

Del Prette, A., Del Prette, Z. A. P., \& Barreto, M. C. M. (2006). Treinamento de habilidades sociais em grupo com estudantes de psicologia: Avaliando um programa de intervenção. In Bandeira, M., Del Prette, Z. A. P., \& Del 
Prette, A. (Orgs.). Estudos sobre habilidades sociais e relacionamento interpessoal. São Paulo: Casa do Psicólogo, 217-234.

Del Prette, Z. A. P. \& Del Prette, A. (2010). Habilidades sociais e análise do comportamento: proximidade histórica e atualidades. Revista Perspectivas, 1 (2), 104-115.

Freire, P. (2009). Educação como Prática da liberdade . Rio de Janeiro: Paz e Terra.

Freire, P. (2011). Saberes necessários à prática educativa: Pedagogia da autonomia. São Paulo: Paz e Terra.

Kumar, M. E., Silva, J. M. T. \& Paixão, M. P. (2007). Os projetos de vida nos estudantes do ensino superior: relações com o otimismo e autoeficácia de carreira. Psychologica, 44, 45-62.

Morais, R. (2001). Sala de aula: que espaço é este? (14a . ed.). São Paulo: Papirus.

Novais, E. (2004). É possível ter autoridade em sala de aula sem ser autoritário? Linguagem e ensino, 7(1), 15-51.

Parker, J. D. A., Sumnerfeldt, L. J., Hogan, M. J., \& Majestic, S. A. (2004). Emotional intelligence and academic sucess examining the transition from high scholl to university. Personality and Individual Differences, 36, 163-172.

Perrenoud, P. (2000). Dez novas competências para ensinar. Porto Alegre: Artmed

Ribas, M. M. H. (2005). Formação de professores, escolas, práticas e saberes. Paraná: UEPG.

Roncaglio, S. M. (2004). A relação professor-aluno na educação superior: $A$ influência da gestão educacional. [Online]. Psicologia: Ciência e Profissão, 24(2), 100-111. doi.org/10.1590/ S1414-98932004000200011 [2013, 5 de maio].
Seco, G., Casimiro, M., Pereira, M., Dias, M., \& Custódio, S. (2005). Para uma abordagem psicológica da transição do Ensino Secundário para o Ensino superior: Pontes e alçapões. Edição Instituto Politécnico de Leiria: Leiria.

Silva, L. V. de C. (2010). As competências do servidor técnico-administrativo na reestruturação do ensino superior público: Estudo no campus da Universidade Federal do Ceará no Cariri (Dissertação de Mestrado). Cariri.

Silva, R. S., \& Nascimento, I. (2012). Estudantes maiores de 23 anos em psicologia: Motivações e processo de integração. Revista Brasileira de Orientação Profissional, 13(1), 37-47.

Soares A. B. e Del Prette, Z. (2013). Guia teórico prático para superar as dificuldades interpessoais na Universidade, Curitiba , Appris.

Soares, A. B., Mello, T. V. S. \& Baldez, M.O.M. (2011). Vivências acadêmicas em estudantes universitários do Estado do Rio de Janeiro. Interação em Psicologia, 15 (1), 56-59.

Soares, A. P., Guisande, A. M., Almeida, L. S., \& Páramo, F. M. (2008). Academic achievement in first-year portuguese college students: The role of academic preparation and learning strategies. Internacional Journal of Psychology, 44, 204-212.

Vasconcellos, C. S. (2004). (In)disciplina: Construção da disciplina consciente $e$ interativa em sala de aula e na escola. (15 ${ }^{\text {a }}$. ed.). São Paulo: Libertad.

Washington, M. G., Alves, L., Arruda, J. R, Netto, T. M., Korenchendler, A. S., Santos, N. dos, Bispo, M. A., \& Machado, A. M. D. (2006). Projeto político pedagógico institucional UERJ (PPI-UERJ). 